\title{
REMOVAL OF HEXAVALENT CHROMIUM FROM AQUEOUS SOLUTION USING ACTIVATED CARBON DERIVED FROM PALMYRA PALM FRUIT SEED
}

\author{
A. Kannan and S. Thambidurai* \\ Department of Industrial Chemistry, Alagappa University, Karaikudi-630003, Tamil Nadu, \\ India
}

(Received March 6, 2007; revised February 13, 2008)

\begin{abstract}
In this study, removal of chromium(VI) from aqueous solutions by Palmyra palm fruit seed carbon (PPFSC) and commercial activated carbon (CAC) was investigated. The metal adsorption capacity has been studied as a function of contact time, $\mathrm{pH}$ and carbon dosage. The adsorption yields increased with the increasing of adsorbent dosage and contact time, and subsequently reached the equilibrium. The suitability of the Freundlich and Langmuir models were also investigated for each chromium sorbent system. In order to understand the reaction mechanism, kinetic data has been studied using pseudo first order rate equation. The Lagergren's constants were calculated for different initial concentrations of metal ions. The chromium(VI) ions could be rapidly removed from the sorbents by treatment with $\mathrm{HCl}$ acid and at the same time the regenerated sorbent could be used again to adsorb heavy metal ions. The suitability of this material for treatment of tannery wastewater was also examined.
\end{abstract}

KEY WORDS: Adsorption; Chromium(VI) removal; Palmyra palm fruit seed carbon; Regeneration; Langmuir and Freundlich isotherm; Pseudo first order kinetics

\section{INTRODUCTION}

Heavy metals are major pollutants in marine; ground and industrials, and even in treated waste water. The presence of these metals in the environment has been a great concern because of their toxic nature and other adverse effects on receiving waters. Among these heavy metals are chromium, copper and zinc, and ingestion beyond the permissible quantities can cause various chronic disorders in human beings. It is well known that heavy metals can damage nerves, liver and bones, and they also block functional groups of essential enzymes [1]. Also, acute systemic poisoning can result from high exposure to hexavalent chromium [2]. Most of the chromium ions in wastewater especially hexavalent chromium originates from industries such as electroplating, metal finishing and magnetic tape manufacturing. For these industrial groups, chromium is a problematic one. Tanning is one of the oldest and fastest growing industries in India. Chromium, which is on the top priority list of toxic pollutants defined by the US Environmental Protection Agency (EPA) exists in nature mainly in two oxidation states +3 and +6 . It is a bio element in the +3 state but mutagenic in the +6 state. Therefore, the speciation of chromium in contaminated environment becomes critical for understanding its fate and exposure. The hydrolysis behavior of $\mathrm{Cr}(\mathrm{III})$ is complicated and it produces mononuclear species $\mathrm{Cr}(\mathrm{OH})^{2+}, \mathrm{Cr}(\mathrm{OH})_{2}{ }^{+}, \mathrm{Cr}(\mathrm{OH})_{4}{ }^{-}$and $\mathrm{Cr}(\mathrm{OH})_{3}{ }^{0}$, the polynuclear species $\mathrm{Cr}_{2}(\mathrm{OH})_{2}$ and neutral species $\mathrm{Cr}_{3}(\mathrm{OH})_{4}{ }^{0}$. The hydrolysis of $\mathrm{Cr}^{6+}$ produces only neutral and anionic species. At $\mathrm{pH}$ greater then $6.5, \mathrm{Cr}(\mathrm{VI})$ exists in the form of $\mathrm{CrO}_{4}{ }^{2-}$. Chromium(VI) compounds are found to be more toxic than $\mathrm{Cr}(\mathrm{III})$ compounds because of their high solubility in water and consequently high mobility. The drinking water guideline recommended by the US EPA is $100 \mu \mathrm{g} / \mathrm{L} \mathrm{Cr}(\mathrm{VI})$.

Several metal ion removal techniques have been targeted as possible solutions. Ion exchange [3], reduction [4], chemical precipitation [5], polymer based membrane separation [6, 7], adsorption [8], electrochemical precipitation [9], solvent extraction [10], cementation [11] and electro kinetic remediation [12] are among the available methods to accomplish the reduction of metal concentration. Nevertheless many of these approaches are marginally cost effective or

*Corresponding author. E-mail: sthambi01@yahoo.co.in 
difficult to implement in developing countries. Therefore, the need arises for a treatment strategy that is simple and robust, and also addresses local resources and constraints. Adsorption is an effective and that versatile method for removing chromium particularly when combined with appropriate regeneration steps. This solves the problems of sludge disposal and renders the system more economically viable especially if low cost adsorbents are used. A variety of activated carbons are commercially available but very few of them are selective for heavy metals and most of them are very costly [13]. Despite the prolific use of activated carbon [14], in wastewater treatment the price of this material is quite expensive and there is a definite need for substitute materials to suit these demanding applications. The solid materials should be able to be regenerated with simultaneous quantitative recovery. For the past few years there has been a developing interest in the preparation of low cost adsorbents as alternatives to activated carbon in water and wastewater treatment processes. In several previous reports, many investigators have studied the feasibility of less expensive materials such as alginate beads [15], wheat straw [16], carbon develop from waste material [17], biosorbents [18], activated sludge [19], fly ash [20], and agricultural waste [21], for the removal of chromium from waste water. However the problems associated with these adsorbents are the regeneration and recovery processes, which made them unattractive for wider commercial applications. This calls for a research effort to develop an industrially viable, cost effective and environmentally compatible technology for the removal of chromium from wastewater. In this study, we have derived a low cost activated carbon from agricultural waste, namely Palmyra palm fruit seed for the removal of hexavalent chromium from synthetic waste water. The same set of experiments was also conducted with a commercial activated carbon for comparison purpose. Palmyra palm tree (Borassus Flabellifer Arecaceae) is a largely populated tree in south India.

\section{Preparation of PPFSC}

\section{EXPERIMENTAL}

Palmyra palm fruit seed was cut into small pieces and air-dried. Then it was treated with concentrated sulfuric acid in a ratio of 2:1 (PPFS: $\left.\mathrm{H}_{2} \mathrm{SO}_{4}\right)$ and the resulting product was kept in oven at $200{ }^{\circ} \mathrm{C}$ for $10 \mathrm{~h}$. The carbonised material was washed with distilled water to remove the free acid and then dried at $105{ }^{\circ} \mathrm{C}$. The carbon obtained from Palmyra palm seed as well as commercial activated carbon (SD fine chemicals), were sieved to an average diameter of about $0.01125 \mathrm{~mm}$ for adsorption experiments. The characterization of carbon [22] was done by ISI procedure. The characteristics of PPFSC and CAC are summarized in Table 1.

Table 1. Characteristics of Palmyra palm fruit seed carbon (PPFSC) and commercial activated carbon (CAC).

\begin{tabular}{|c|l|c|c|}
\hline S. No. & Control test & PPFSC & CAC \\
\hline 1. & Bulk density (g/L) & 0.67 & 0.56 \\
2. & Moisture \% & 0.47 & 0.27 \\
3. & Ash \% & 3.25 & 1.20 \\
4. & Solubility in water \% & 1.40 & 3.599 \\
5. & Solubility in $0.25 \mathrm{M}(\mathrm{HCl}) \%$ & 2.97 & 5.41 \\
6. & pH & 2.26 & 9.50 \\
7. & Decolorizing power $(\mathrm{mg} / \mathrm{g})$ & 15.00 & 2.25 \\
8. & Phenol number & 76.00 & 88.00 \\
9. & Ion exchange capacity $(\mathrm{m}$. Equiv/g) & 0.19 & Nil \\
10. & Surface area $\left(\mathrm{m}^{2} / \mathrm{g}\right)$ & 184.60 & 421.00 \\
11. & Porosity \% & 12.16 & 2.40 \\
\hline
\end{tabular}


Instrument

The chromium(VI) concentration measurements were carried out using Perkin-Elmer 3100 atomic absorption spectrometer. The solution $\mathrm{pH}$ was measured with Hanna $\mathrm{pH}$ meter using a combined glass electrode. The shaking was carried out in orbital electronic shaker and centrifugation was performed in Hittich EBA20 centrifuge.

\section{Adsorption studies}

Stock solution of $\mathrm{Cr}(\mathrm{VI})$ was prepared by dissolving appropriate amount of $\mathrm{K}_{2} \mathrm{Cr}_{2} \mathrm{O}_{7}$ in distilled water. This solution was diluted to obtain standard solution containing 3-20 mg/L. Known amounts of PPFSC or CAC were added and solution $\mathrm{pH}$ was adjusted using dilute hydrochloric acid or sodium hydroxide. The solution was agitated at $750 \mathrm{rpm}$ in orbital shaker at $30^{\circ} \mathrm{C}$. The solutions were centrifuged and the amount of $\mathrm{Cr}(\mathrm{VI})$ in the supernatant was measured by using atomic absorption spectrometer. Adsorption isotherms were carried out with different initial concentrations of $\mathrm{Cr}(\mathrm{VI})$, while the carbon dosage was fixed for the effect of $\mathrm{pH}$. Control experiments were also carried out without adsorbents. The percentage of $\mathrm{Cr}(\mathrm{VI})$ adsorption from aqueous solution was computed by the following equation:

Adsorption $(\%)=\frac{C_{I}-C_{F}}{C_{I}} \times 100$

where $\mathrm{C}_{\mathrm{I}}$ and $\mathrm{C}_{\mathrm{F}}$ are the initial and final chromium(VI) concentrations.

In this study, the contact time was varied between 180 to $300 \mathrm{~min}$, the solution $\mathrm{pH}$ of 1.0 to 8.0 and the initial chromium(VI) concentration varying from 3 to $20 \mathrm{mg} / 100 \mathrm{~mL}$.

\section{RESULTS AND DISCUSSION}

\section{Analysis of PPFSC and CAC by SEM and FTIR}

The morphological analysis of PPFSC and CAC was performed by scanning electron microscopy. Figures 1 and 2 show the structure of PPFSC and CAC. The irregular surface, bigger holes and cave type of openings are seen on the surface of PPFSC. The $\mathrm{pH}$ of PPFSC was found to be 2.26 while CAC found to be 9.84 , $\mathrm{pH}$ value of PPFSC suggested that the carbon is acidic in nature where as CAC is basic in nature. CAC showed higher surface area of $421 \mathrm{~m}^{2} / \mathrm{g}$ than PPFSC, which showed the value of $184.60 \mathrm{~m}^{2} / \mathrm{g}$. The high surface area CAC was mainly due to high temperature carbonisation adopted for CAC in preparation than PPFSC. Commercial carbons have a typical surface area range of about 400 to $1600 \mathrm{~m}^{2} / \mathrm{g}$ [23], ion exchange sites compensate lower surface area of PPFSC, by which more removal of metal ion like chromium(VI) may be achieved. Moreover, the high moisture content of PPFSC suggests that the acid treatment has made. The carbon shows more porous, which was shown by porosity value of $12.16 \%$. This is lower than 2.40 of CAC. The fixed carbon content of a given dry activated carbon is normally obtained by subtracting the ash content from 100, which represents the inorganic portion of the carbon. The ash content indicates that PPFSC has more carbon content. The commercial variety has the least value of ash content indicating that it might have been derived from higher grades of coal such as sub bituminous or semi anthracite. From this it can be concluded that PPFSC is more promising when compared to CAC. 

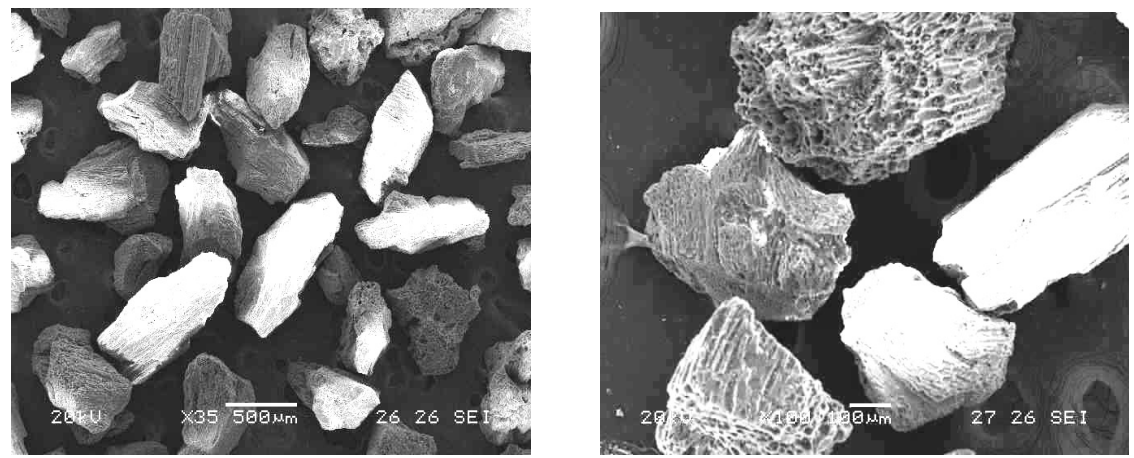

Figure 1. SEM-structure of PPFSC (1 x 35) and (1 x 100).
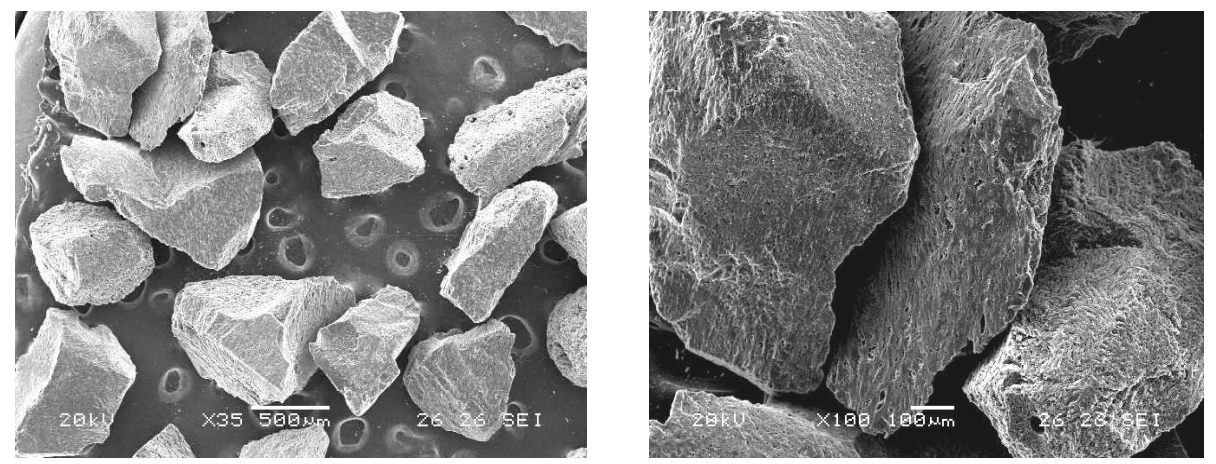

Figure 2. SEM-structure of CAC ( 1 x 35) and (1 x 100).

The FTIR spectra of PPFSC and CAC are presented in Figure 3 (a) PPFSC and (b) CAC. The FTIR spectra of PPFSC show the absorption band at $3736 \mathrm{~cm}^{-1}$ and $3368 \mathrm{~cm}^{-1}$ corresponding to the stretching vibration of $\mathrm{O}-\mathrm{H}$ and $\mathrm{N}-\mathrm{H}$, respectively. Strong peaks at 2921 $\mathrm{cm}^{-1}$ and $2852 \mathrm{~cm}^{-1}$ indicate the presence of $\mathrm{C}-\mathrm{H}$, peaks at $2360 \mathrm{~cm}^{-1}$ and $2343 \mathrm{~cm}^{-1}$ indicate the presence of $\mathrm{C} \equiv \mathrm{C}$. It was reported that the absorption band of both carboxylic and carboxylate groups was about $1716 \mathrm{~cm}^{-1}, 1706 \mathrm{~cm}^{-1}$ and $1669 \mathrm{~cm}^{-1}$, respectively [24] and these major functional groups are responsible for metal ion sorption. The strong peak at $1595 \mathrm{~cm}^{-1}$ is due to $\mathrm{C}=\mathrm{C}$ stretching vibration. The strong peaks at $1201 \mathrm{~cm}^{-1}$ and $1167 \mathrm{~cm}^{-1}$ are due to the presence of polymeric $-\mathrm{SO}_{3} \mathrm{H}$ group indicates the favorable for ion exchange mechanism. The presence of sulfonic acid group is confirmed by peaks at $831 \mathrm{~cm}^{-1}$ and $786 \mathrm{~cm}^{-1}$ due to the stretching vibration of $\mathrm{S}=\mathrm{O}$.

The FTIR spectra of CAC show weak absorption bands at $3803 \mathrm{~cm}^{-1}$ and $3690 \mathrm{~cm}^{-1}$ due to the stretching vibrations of O-H group. Peaks at $2920 \mathrm{~cm}^{-1}$ and $2849 \mathrm{~cm}^{-1}$ indicate the presence of $\mathrm{C}-\mathrm{H}$, while peaks at $2362 \mathrm{~cm}^{-1}$ and $2342 \mathrm{~cm}^{-1}$ are due to $\mathrm{C} \equiv \mathrm{C}$ stretching vibration. The peak at $1561 \mathrm{~cm}^{-1}$ is due to aromatic $\mathrm{C}=\mathrm{C}$ stretching vibration while the weak absorption bands at 1160 $\mathrm{cm}^{-1}$ and $1118 \mathrm{~cm}^{-1}$ are due to the presence of $-\mathrm{SO}_{3} \mathrm{H}$ group, indicates the favorable for ion exchange mechanism. The weak absorption bands at $1051 \mathrm{~cm}^{-1}$ and $1020 \mathrm{~cm}^{-1}$ are the $\mathrm{C}=\mathrm{O}$ stretching vibration. 


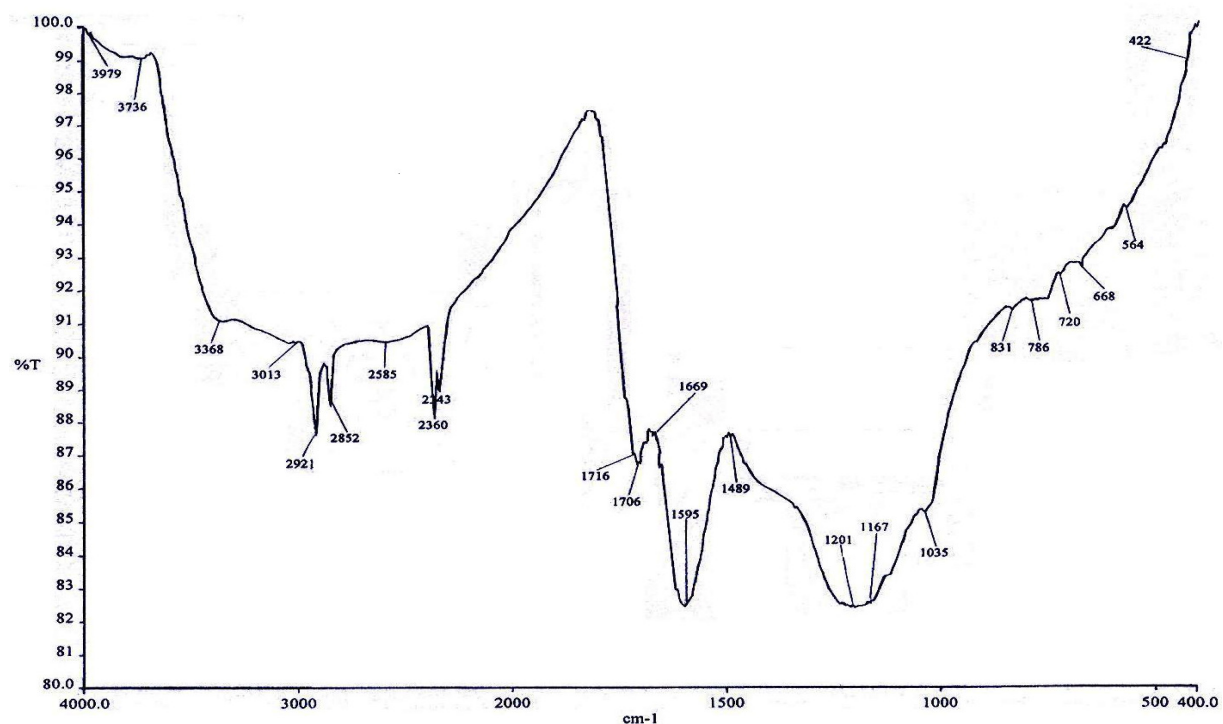

(a) FTIR plot of PPFSC

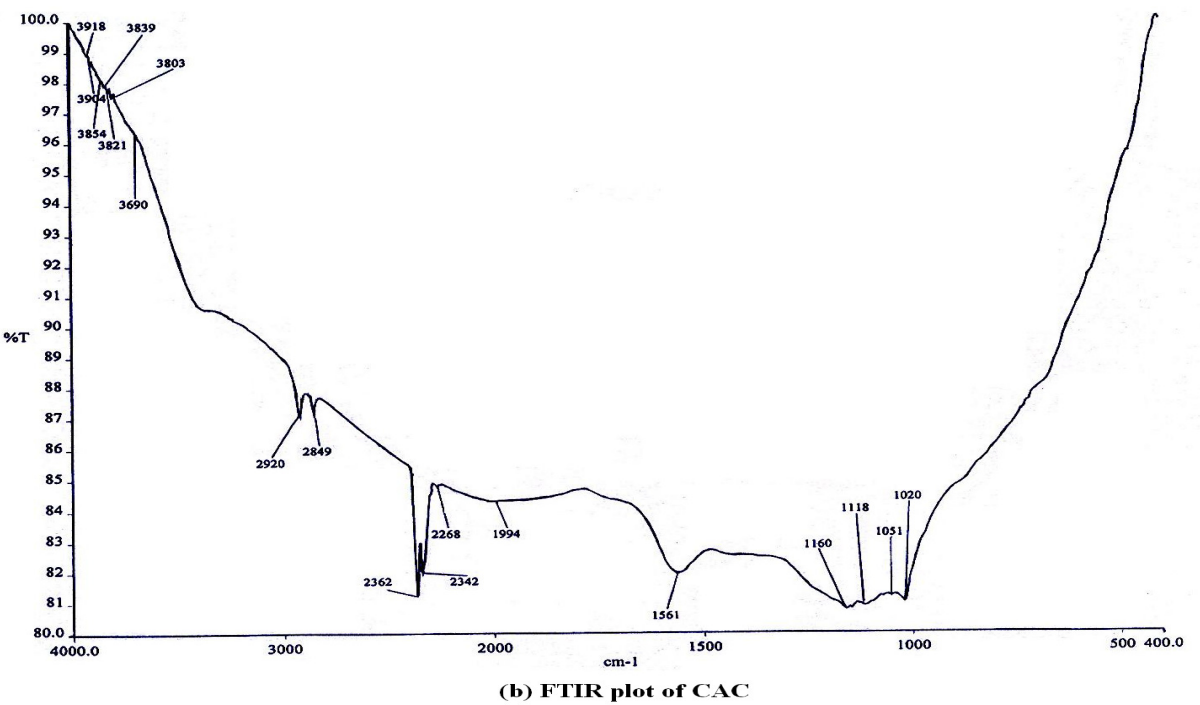

Figure 3. FTIR plots of (a) PPFSC and (b) CAC.

Summary of carbon characteristics in Table 1 shows that PPFSC has higher bulk density and ion exchange capacity than CAC. The moisture content in PPFSC suggests that the acid treatment has made the carbon porous. Even though PPFSC shows lower surface area when compared with $\mathrm{CAC}$, it shows considerable ion exchange capacity through which the $\mathrm{Cr}(\mathrm{VI})$ removal may be taking place. 


\section{Effect of contact time}

The effect of contact time on the removal of $\mathrm{Cr}(\mathrm{VI})$ was studied in the $\mathrm{pH}$ range 1.0 to 2.0 for PPFSC and $\mathrm{pH} 2.0$ for CAC. The amount of adsorbent was fixed $500 \mathrm{mg} / 100 \mathrm{~mL}$ for both carbons and the solutions were equilibrated. An aliquot of the solution was periodically with drawn at an interval of one hour and analyzed using atomic absorption spectrometer to establish the $\mathrm{Cr}(\mathrm{VI})$ removal. The results are shown in Figure 4. The percent of removal increases with time and attains equilibrium at $3 \mathrm{~h}$ for PPFSC and $5 \mathrm{~h}$ for CAC. This indicates that the optimum time required for maximum $\mathrm{Cr}(\mathrm{VI})$ removal by PPFSC would be 1.6 times less than that required by $\mathrm{CAC}$.

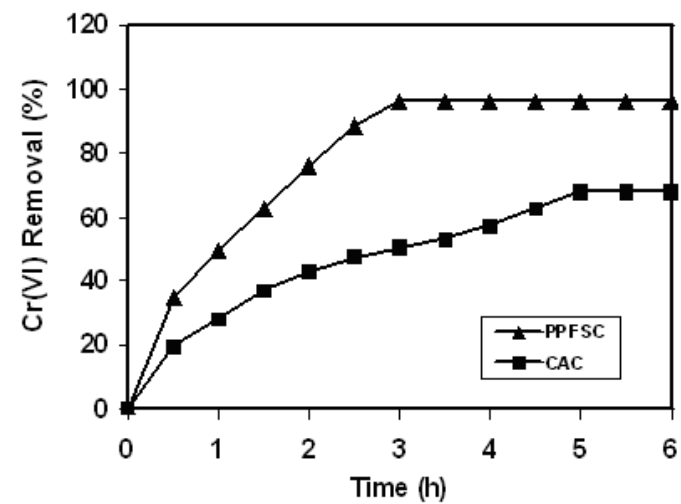

Figure 4. Effect of contact time for the removal of chromium(VI) by PPFSC and CAC.

\section{Effect of $p H$}

$\mathrm{pH}$ is one of the most important parameter controlling the metal ion adsorption process. The effect $\mathrm{pH}$ on the adsorption of $\mathrm{Cr}(\mathrm{VI})$ is attributed to interaction between ions in solution and complex formed at the adsorbent surface. The fact that $\mathrm{Cr}(\mathrm{VI})$ in aqueous solution can form different species in the solution at various $\mathrm{pH}$ ranges.

This study was carried out at initial $\mathrm{Cr}(\mathrm{VI})$ concentration of $20 \mathrm{mg} / \mathrm{L}$. The adsorption of $\mathrm{Cr}(\mathrm{VI})$ on the prepared adsorbents decreased with increasing $\mathrm{pH}$. Figure 5 shows that PPFSC and $\mathrm{CAC}$ are active in acidic range especially at low $\mathrm{pH}$ range. The maximum adsorption of $\mathrm{Cr}(\mathrm{VI})$ species on the two different adsorbents was found to be optimum $\mathrm{pH} 2.0$ and negligible at $\mathrm{pH}$ over 8.0. $\mathrm{Cr}(\mathrm{VI})$ can exist in several stable forms such as $\mathrm{CrO}_{4}{ }^{2-}, \mathrm{HCrO}_{4}{ }^{2-}, \mathrm{Cr}_{2} \mathrm{O}_{7}{ }^{2-}$ and $\mathrm{HCr}_{2} \mathrm{O}_{7}{ }^{-}$, and the relative abundance of a particular complex depends on the concentration of chromium ion and $\mathrm{pH}$ of the solution. At low $\mathrm{pH}$, the sorbent is positively charged because of the protonation where as the sorbate like dichromate ions exists mostly as an anion, leading to an electrostatic attraction between the sorbent and the sorbate. This results in increased adsorption at low $\mathrm{pH}$. As the $\mathrm{pH}$ of the solution increases, the sorbent undergoes deprotonation, and the adsorption capacity decreases. Therefore all subsequent studies were carried out at $\mathrm{pH}$ 2.0. The high removal of $\mathrm{Cr}(\mathrm{VI})$ at low $\mathrm{pH}$ was reported earlier using different adsorbents [17, 20]. 


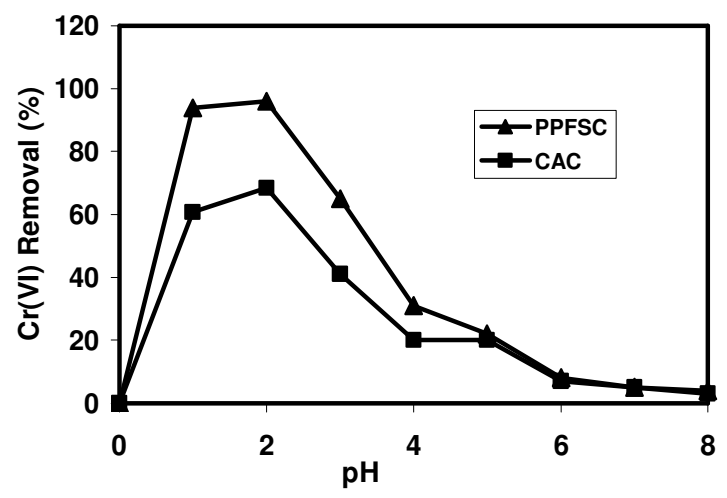

Figure 5. Effect of $\mathrm{pH}$ on the removal of chromium(VI) by PPFSC and CAC.

\section{Effect of carbon dosage}

The experiments were conducted to find out the minimum amount of carbons required for the removal of $\mathrm{Cr}(\mathrm{VI})$. It is evident that for the quantitative removal of $20 \mathrm{mg} / \mathrm{L}$ of $\mathrm{Cr}(\mathrm{VI})$ in 100 $\mathrm{mL}$ reference solution a minimum dosage of $300 \mathrm{mg}$ is required for $94.6 \%$ removal in the case of PPFSC whereas $500 \mathrm{mg}$ is removed only $68 \%$ by CAC as shown in Figure 6. This clearly shows that PPFSC is more effective than CAC.

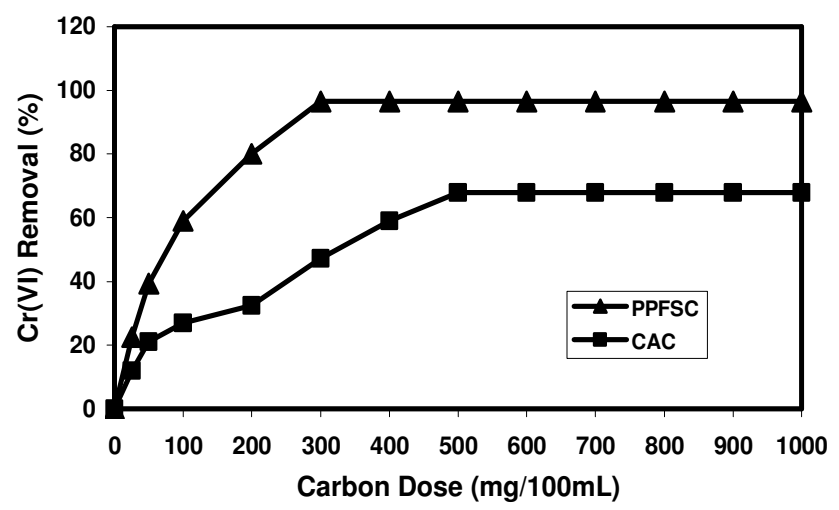

Figure 6. Effect of carbon dosage on the removal of $\mathrm{Cr}(\mathrm{VI})$ by PPFSC and CAC, equilibration time $3 \mathrm{~h}$ for PPFSC and $5 \mathrm{~h}$ for CAC with $20 \mathrm{mg} / \mathrm{L}$ of $\mathrm{Cr}(\mathrm{VI})$.

\section{Desorption studies}

Palmyra palm fruit seed carbon (PPFSC) and commercial activated carbon (CAC) which adsorbed at maximum concentration of $\mathrm{Cr}(\mathrm{VI})$ was used for desorption studies. Desorption of $\mathrm{Cr}(\mathrm{VI})$ was achieved by using $\mathrm{HCl}$ acid strength varying from 0.02-0.2 $\mathrm{M}$. The PPFSC carrying $32.14 \mathrm{mg} \mathrm{Cr}(\mathrm{VI}) / \mathrm{g}$ and $\mathrm{CAC}$ carrying $8.23 \mathrm{mg} \mathrm{Cr}(\mathrm{VI}) / \mathrm{g}$ were placed in the desorption medium and stirred at $750 \mathrm{rpm}$ at $30{ }^{\circ} \mathrm{C}$. The final $\mathrm{Cr}(\mathrm{VI})$ ion concentration in the aqueous phase was determined by using atomic absorption spectrometer and desorption ratio was calculated from the amount of metal ion adsorbed on the carbons and the final metal ion concentration in the desorption medium using the following equation. The results are shown in Figure 7. It is seen 
that $0.2 \mathrm{M} \mathrm{HCl}$ from PPFSC and CAC could desorbs maximum of $86.6 \%$ and $55.5 \%$, respectively. It could be seen that more amount of chromium(VI) could be recovered from PPFSC than CAC.

Desorption ratio $(\%)=\frac{\text { Amount }}{\text { Amount }} \frac{\text { of }}{\text { of }} \frac{\text { metal }}{\text { metal }} \frac{\text { ions }}{\text { ions }} \frac{\text { desorbed }}{\text { adsorbed }} \times 100$

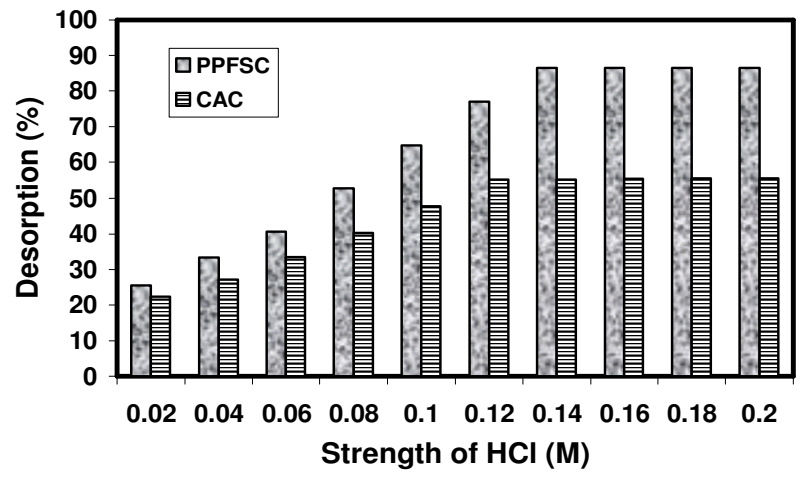

Figure 7. Desorption studies using various strength of $\mathrm{HCl}$ by PPFSC and CAC.

\section{Adsorption isotherms}

Freundlich adsorption isotherm. The Freundlich equation was applied to describe the analytical results on the adsorption. Its empirical result agrees quit well with Langmuir equation and experimental data over a moderate range of adsorbate concentration. It is represented by the equation [25]

$\log \mathrm{x} / \mathrm{m}=\log \mathrm{K}+1 / \mathrm{n} \log \mathrm{C}_{\mathrm{eq}}$

where $\mathrm{Ce}_{\mathrm{q}}$ is the equilibrium concentration $(\mathrm{mg} / \mathrm{L}), \mathrm{x} / \mathrm{m}$ is the amount adsorbed per unit mass of PPFSC or CAC (mg/g), $\mathrm{n}$ is the indication of favorability and $\mathrm{K}$ is the capacity of the adsorbent. Plotting $\log \mathrm{x} / \mathrm{m}$ vs. $\log \mathrm{C}_{\mathrm{eq}}$ gives a straight line with a slope of $1 / \mathrm{n}$ and $\log \mathrm{K}$ is the intercept, and $\mathrm{r}^{2}$ values of PPFSC 0.9920 and CAC 0.9434 shows the linearity. The plots are represented in the Figure 8. The calculated K values were 1.1885 for PPFSC and 1.3646 for CAC while the values of $\mathrm{n}$ were calculated to be 5.1795 and 2.1543 for PPFSC and CAC, respectively. The values of $1<\mathrm{n}<10$ shows favorable adsorption of $\mathrm{Cr}(\mathrm{VI})$ on both PPFSC and CAC [26].

Langmuir adsorption isotherm. Langmuir equation was also applied for adsorption equilibrium for both carbons. The Langmuir model is based on the assumption that maximum adsorption corresponds to monolayer of adsorbate molecules on the adsorbent surface, the constant energy of adsorption given by Langmuir isotherm and there is no transmigration of adsorbate in the plane of the surface.

$\mathrm{C}_{\mathrm{e}} / \mathrm{q}_{\mathrm{e}}=1 / \mathrm{Q}_{0} \mathrm{~b}+\mathrm{C}_{\mathrm{e}} / \mathrm{Q}_{0}$

where $\mathrm{q}_{\mathrm{e}}$ is the amount of solute adsorbed per unit weight of adsorbent $(\mathrm{mg} / \mathrm{g}), \mathrm{C}_{\mathrm{e}}$ is the equilibrium concentration of solute in the bulk solution $(\mathrm{mg} / \mathrm{L}), \mathrm{Q}_{0}$ is the monolayer adsorption capacity $(\mathrm{mg} / \mathrm{g})$ and $\mathrm{b}$ is a constant related to the free energy of adsorption.

The linear plots of $\mathrm{C}_{\mathrm{e}} / \mathrm{q}_{\mathrm{e}}$ vs. $\mathrm{C}_{\mathrm{e}}$ in Figure 9 show that the adsorption obeys Langmuir adsorption model for PPFSC, CAC and $\mathrm{r}^{2}$ values of PPFSC 0.9751 and CAC 0.8232 shows the linearity. $\mathrm{Q}_{0}$ and $\mathrm{b}$ were determined from the plots and found to be $32.14 \mathrm{mg} / \mathrm{g}$ and $1.00 \mathrm{mg} / \mathrm{L}$ 
for PPFSC and $8.23 \mathrm{mg} / \mathrm{g}$ and $2.05 \mathrm{mg} / \mathrm{L}$ for CAC, respectively. The ratio of $\mathrm{Q}_{0}$ between PPFSC and CAC works out to be 3.9052. The essential characteristics of Langmuir isotherm are expressed in terms of a dimensionless constant separation factor or equilibrium parameter RL, which is defined by

$\mathrm{RL}=1 /\left(1+\mathrm{bC}_{\mathrm{o}}\right)$

where $\mathrm{b}$ is the Langmuir constant and $\mathrm{C}_{\mathrm{o}}$ is the initial concentration of $\mathrm{Cr}(\mathrm{VI})$. The parameter indicates the isotherm shapes as shown in Table 2. The observed values of RL between 0 and 1 indicate favorable adsorption of $\mathrm{Cr}(\mathrm{VI})$ on both PPFSC and CAC at the concentration studied at $30{ }^{\circ} \mathrm{C}$. RL values for both PPFSC and CAC are 0.0476 and 0.2500 , respectively.

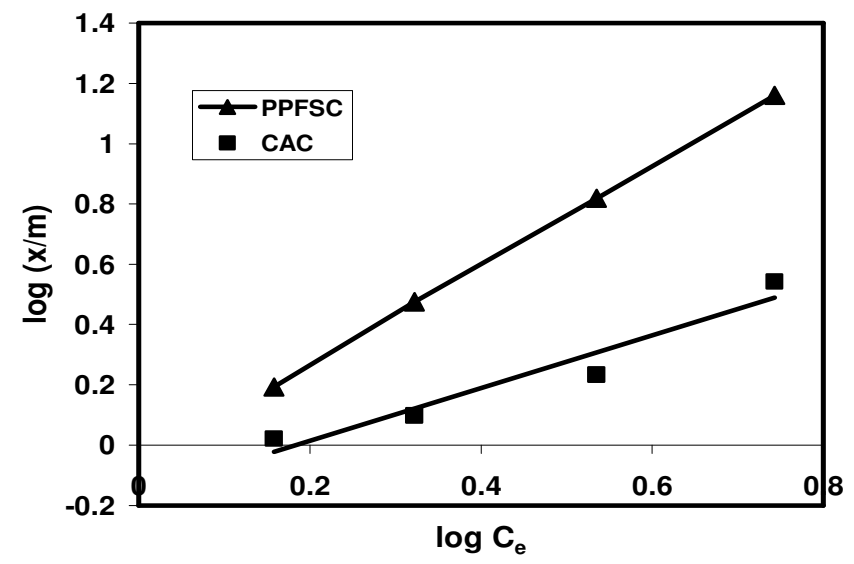

Figure 8. Freundlich adsorption isotherm for chromium(VI) with PPFSC and CAC.

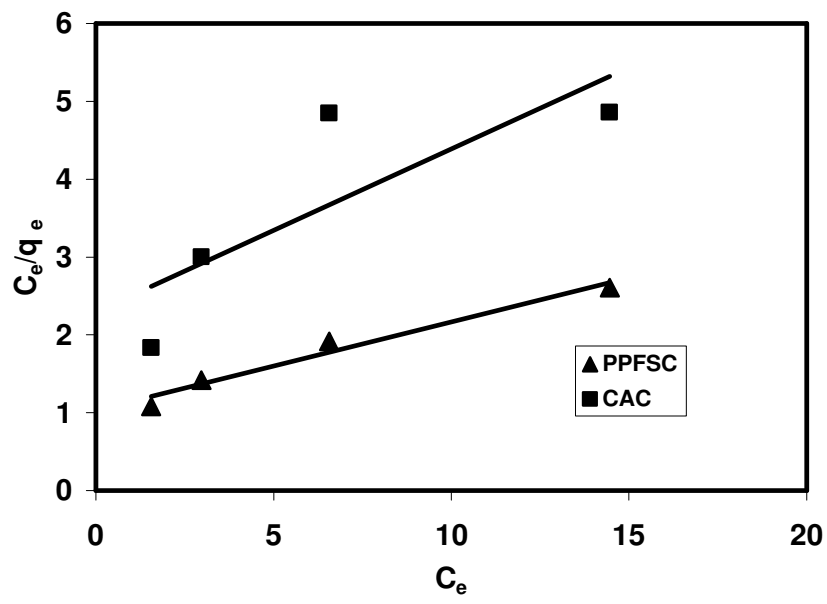

Figure 9. Langmuir adsorption isotherm for chromium(VI) with PPFSC and CAC. 
Table 2. Characteristics of langmuir adsorption isotherms.

\begin{tabular}{|c|l|l|}
\hline S. No. & Separation factor $\mathrm{R}_{\mathrm{L}}$ & Types of Isotherm \\
\hline 1 & $\mathrm{R}_{\mathrm{L}}>1$ & Unfavorable \\
2 & $\mathrm{R}_{\mathrm{L}}=1$ & Linear \\
3 & $0<\mathrm{R}_{\mathrm{L}}<1$ & Favorable \\
4 & $\mathrm{R}_{\mathrm{L}}>0$ & Irreversible \\
\hline
\end{tabular}

Kinetic studies

The kinetics of $\mathrm{Cr}(\mathrm{VI})$ adsorption on both PPFSC and CAC were evaluated by the first order rate expression [27].

$\ln \left(1-\mathrm{U}_{\mathrm{t}}\right)=-\mathrm{K}_{\mathrm{t}}$

where $\mathrm{U}_{\mathrm{t}}=\left(\mathrm{C}_{0}-\mathrm{C}_{\mathrm{t}}\right) /\left(\mathrm{C}_{0}-\mathrm{C}_{\mathrm{e}}\right) . \mathrm{C}_{0}, \mathrm{C}_{\mathrm{t}}$ and $\mathrm{C}_{\mathrm{e}}$ are concentration in $\mathrm{mg} / \mathrm{L}$ of $\mathrm{Cr}(\mathrm{VI})$ at initially, time $\mathrm{t}$ and equilibrium, respectively. A straight-line plot of $\ln \left(1-\mathrm{U}_{t}\right)$ vs. time Figures 10 and 11 indicate that the adsorption process follows the first order kinetics. The straight-line portions of the curves were used for calculating the slope which gives the overall rate constant, $\mathrm{K}$ of the process.

The forward $\left(\mathrm{k}_{1}\right)$ and backward $\left(\mathrm{k}_{2}\right)$ rate constants were calculated using the following equation

$\mathrm{K}=\mathrm{k}_{1}+\mathrm{k}_{2}$

$\mathrm{k}_{2}=\left(\mathrm{k}_{1} / \mathrm{K}_{\mathrm{c}}\right)$

$\mathrm{K}=\mathrm{k}_{1}\left(1+\left(1 / \mathrm{K}_{\mathrm{c}}\right)\right)$

$\mathrm{K}_{\mathrm{c}}=\mathrm{k}_{1} / \mathrm{k}_{2}$

where $\mathrm{K}_{\mathrm{c}}$ is the equilibrium constant. The kinetic data are given in Table 3. It is evident that the forward rate constant is much higher than the backward rate constant suggesting that the rate of adsorption is clearly dominant for both carbon. In order to assess the nature of diffusion process reasonable for the adsorption of $\mathrm{Cr}(\mathrm{VI})$ on PPFSC and CAC, attempts were made to calculate the pore and film diffusion coefficients for various concentration of $\mathrm{Cr}(\mathrm{VI})$ using the following equation [28].

$\mathrm{D}_{\mathrm{p}}=0.03 \mathrm{r}_{\mathrm{o}}^{2} / \mathrm{t}_{1 / 2}$

$\mathrm{D}_{\mathrm{f}}=0.23 \mathrm{r}_{\mathrm{o}} \partial \mathrm{C}^{*} / \mathrm{Ct}_{1 / 2}$

where $D_{p}$ and $D_{f}$ are the pore and film diffusion coefficients, respectively, both expressed in $\mathrm{cm}^{2} / \mathrm{s}, \mathrm{r}_{\mathrm{o}}{ }^{2}$ is the radius of the sorbent expressed in $\mathrm{cm}$, and $\mathrm{t}_{1 / 2}$ is the half-life period in sec. $\partial$ is the film thickness expressed in $\mathrm{cm}$ and $\mathrm{C}^{*} / \mathrm{C}$ is equilibrium loading of the sorbent. According to the adsorption of heavy metals on carbon surface, for film diffusion to be the rate determining process, the value of film diffusion co-efficient should be between $10^{-6}-10^{-8} \mathrm{~cm}^{2} / \mathrm{s}$ [29]. If pore diffusion were to be the rate-limiting factor, the pore diffusion co-efficient must be closer to the range of $10^{-11}-10^{-13} \mathrm{~cm}^{2} / \mathrm{s}$. It is evident that the removal of $\mathrm{Cr}(\mathrm{VI})$ follows film diffusion process, since the coefficient values are close to the range of $10^{-6}-10^{-8} \mathrm{~cm}^{2} / \mathrm{s}$ and these values are shown in Table 4. 


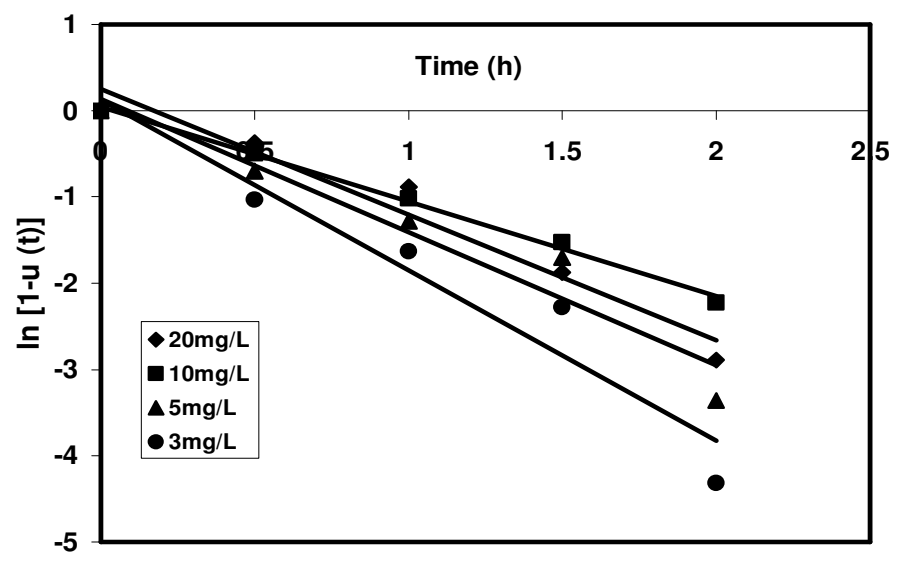

Figure 10. Lagergren plots for the removal of Cr(VI) by PPFSC.

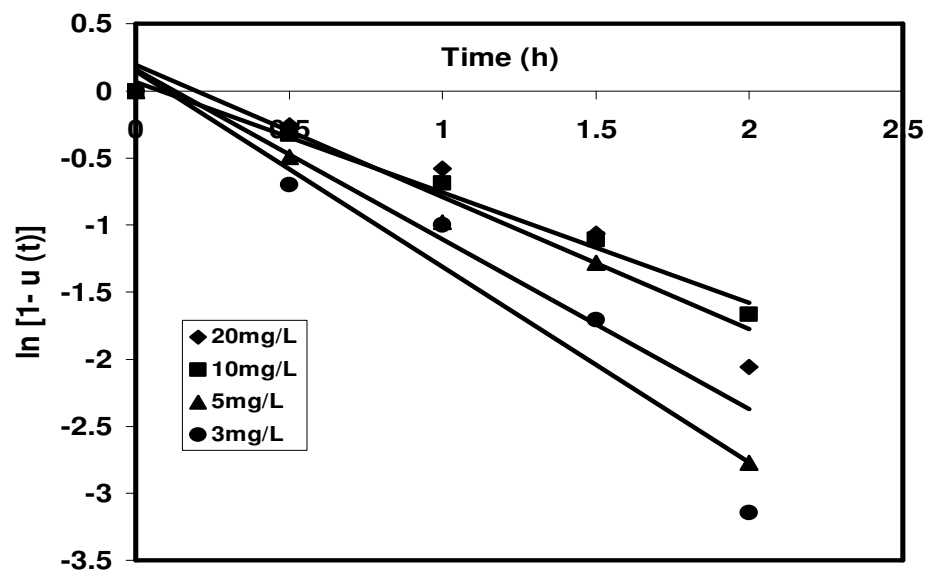

Figure 11. Lagergren plots for the removal of $\mathrm{Cr}(\mathrm{VI}) \mathrm{By} \mathrm{CAC}$.

Table 3. Rate constants for the removal of chromium(VI) by PPFSC and CAC.

\begin{tabular}{|c|c|c|c|c|}
\hline Carbon & $\begin{array}{c}\text { Initial concentration of } \\
\mathrm{Cr}(\mathrm{VI}) \text { ions }(\mathrm{mg} / \mathrm{L})\end{array}$ & $\begin{array}{c}\text { Overall rate constant } \\
\mathrm{K} \mathrm{h}^{-1}\left(\mathrm{k}_{1}+\mathrm{k}_{2}\right)\end{array}$ & $\begin{array}{c}\text { Forward rate } \\
\text { constant } \mathrm{k}_{1} \mathrm{~h}^{-1}\end{array}$ & $\begin{array}{c}\text { Backward rate } \\
\text { constant } \mathrm{k}_{2} \mathrm{~h}^{-1}\end{array}$ \\
\hline \multirow{3}{*}{ PPFSC } & 20 & 0.5600 & 0.4077 & 0.1523 \\
& 10 & 0.6000 & 0.3942 & 0.2058 \\
& 5 & 0.6000 & 0.3576 & 0.2869 \\
& 3 & 0.7000 & 0.4131 & 0.2869 \\
\hline \multirow{3}{*}{ CAC } & 20 & 0.5833 & 0.4818 & 0.1015 \\
& 10 & 0.5833 & 0.4836 & 0.0997 \\
& 5 & 0.6333 & 0.4750 & 0.1583 \\
\hline
\end{tabular}

Bull. Chem. Soc. Ethiop. 2008, 22(2) 
Table 4. Diffusion coefficient of the sorbents for the removal of chromium(VI) by PPFSC and CAC.

\begin{tabular}{|c|c|c|c|}
\hline Sorbent & $\begin{array}{c}\text { Initial concentration of } \\
\mathrm{Cr}(\mathrm{VI}) \text { ions }(\mathrm{mg} / \mathrm{L})\end{array}$ & $\begin{array}{c}\text { Film diffusion }\left(\mathrm{D}_{\mathrm{f}}\right) \\
\left(\mathrm{cm}^{2} / \mathrm{s}\right)\end{array}$ & $\begin{array}{c}\text { Pore diffusion } \\
\left(\mathrm{D}_{\mathrm{p}}\right)\left(\mathrm{cm}^{2} / \mathrm{s}\right)\end{array}$ \\
\hline \multirow{5}{*}{ PPFSC } & 20 & $2.0996 \times 10^{-9}$ & $2.1307 \times 10^{-10}$ \\
& 10 & $2.2829 \times 10^{-9}$ & $2.0442 \times 10^{-10}$ \\
& 5 & $2.2829 \times 10^{-9}$ & $1.8544 \times 10^{-10}$ \\
$\mathrm{CAC}$ & 3 & $2.6634 \times 10^{-9}$ & $1.8876 \times 10^{-10}$ \\
\hline & 20 & $2.2193 \times 10^{-9}$ & $2.4985 \times 10^{-10}$ \\
& 10 & $2.2193 \times 10^{-9}$ & $2.5076 \times 10^{-10}$ \\
& 5 & $2.4095 \times 10^{-9}$ & $2.4630 \times 10^{-10}$ \\
& 3 & $2.6634 \times 10^{-9}$ & $2.3595 \times 10^{-10}$ \\
\hline
\end{tabular}

Experiments with tannery industrial wastewater

The suitability of the carbon derived from Palmyra palm fruit seed carbon (PPFSC) and commercial activated carbon (CAC) was also evaluated for the removal of chromium(VI) in tannery industrial wastewater. Experiments were conducted with chromium(VI) effluent from tannery industry around Vellore district, Tamil Nadu, India. The characteristic of the wastewater is shown in Table 5. The wastewater was taken and diluted 20 times because of its high $\mathrm{Cr}(\mathrm{VI})$ concentration. The experiments were conducted at optimum $\mathrm{pH}$ with $100 \mathrm{~mL}$ of $167 \mathrm{mg} / \mathrm{L}$ of $\mathrm{Cr}(\mathrm{VI})$ solution with different carbons doses of PPFSC and CAC. Then the solutions were equilibrated for $5 \mathrm{~h}$. The percent of $\mathrm{Cr}(\mathrm{VI})$ removal in each instance was established by usual procedure. Figure 12 shows that maximum $\mathrm{Cr}(\mathrm{VI})$ removal was $89 \%$ using $3.5 \mathrm{~g}$ of PPFSC and only $63 \%$ achieved with $5.75 \mathrm{~g}$ of CAC. This indicates that PPFSC is more effective for treatment of tannery wastewater when compared to CAC.

Table 5. The characteristics of tannery industrial wastewater.

\begin{tabular}{|l|c|}
\hline Parameters & Concentration $(\mathrm{mg} / \mathrm{L})$ \\
\hline $\mathrm{pH}$ & 8.5 \\
\hline Total solids & 8540 \\
\hline Chromium(VI) & 4520 \\
\hline Potassium & 87.0 \\
\hline Magnesium & 138.3 \\
\hline Sodium & 748.5 \\
\hline Chloride & 679.0 \\
\hline Sulfate & 520.0 \\
\hline
\end{tabular}




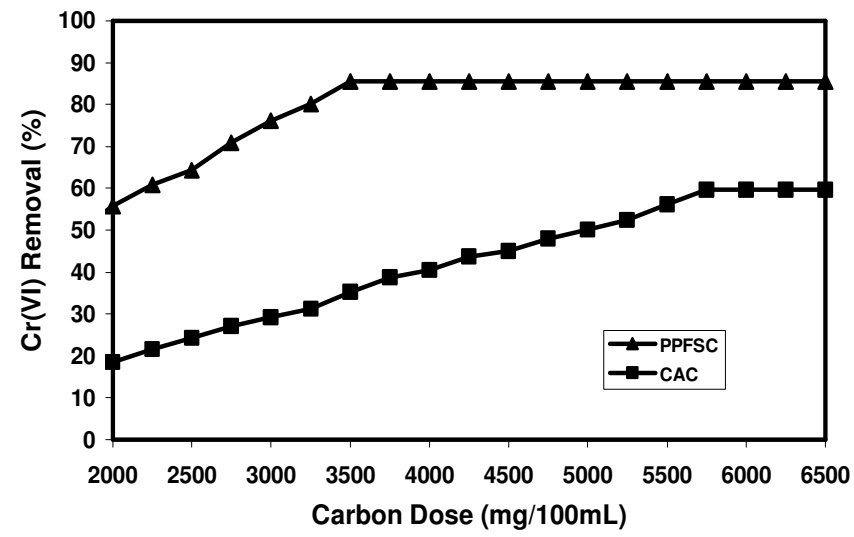

Figure 12. Application to tannery wastewater using various amounts of carbon on the removal of $\mathrm{Cr}(\mathrm{VI})$ by PPFSC and CAC.

\section{CONCLUSIONS}

This study shows that Palmyra palm fruit seed carbon was an effective adsorbent for the removal and recovery of $\mathrm{Cr}(\mathrm{VI})$ from aqueous solution. Adsorption of $\mathrm{Cr}(\mathrm{VI})$ was highly $\mathrm{pH}$ dependent and the results showed that the optimum $\mathrm{pH}$ for the removal was found to be in the range of 1.0 to 2.0, at which $\mathrm{Cr}(\mathrm{VI})$ exists as the most easily adsorbed form. These two carbons confirm to Freundlich and Langmuir equations based on the assumption of monolayer adsorption. $\mathrm{Q}_{0}$ values show that 3.9 times as higher as commercial activated carbon shows the higher adsorption capacity of PPFSC. The adsorption capacity of PPFSC is found to be higher than CAC based upon its carboxylic and carboxylate as major functional groups that responsible for $\operatorname{Cr}(\mathrm{VI})$ sorption. It is also abundantly available as a waste material, which can be processed as an alternative to replace of CAC. The adsorption of $\mathrm{Cr}(\mathrm{VI})$ on both carbons has been well fitted for the reversible first order kinetics with film diffusion being the essential rate-controlling step. The kinetic data would be useful for fabrication and designing the wastewater treatment plants. It is concluded that in addition to the above advantages, activated carbon prepared from Palmyra palm fruit seed could also be considered for commercial application.

\section{AKNOWLEDGEMENTS}

The authors are very much thankful to Asst. Prof. Dr. M. Singanan, Ambo College, Ethiopia and Prof. Dr. K. Srinivasan, Govt. College of Engineering, Salem, India, for their assistance to complete this work. The authors also thank to P.T.Lee.C.N.C.E.T, Chairmen, Secretary, Trust members and Principal for providing a lot of help to finish this work.

\section{REFERENCES}

1. Nourbakhsh, M.N.; Kilicarslan, S.; Ilhan, S.; Ozdag, H. Sp. Chem. Eng. J. 2002, 85, 351.

2. Ulmanu, M.; Anger, I.; Lakatos, J.; Aurn, G. in Proceeding of the First International Conference on Environmental Research and Assessment, Bucharest, Romania, March 23-27; 2003, pp. 185-192. 
3. Rengaraj, S.; Joo, C.K.; Kim, Y.; Yi, J. J. Haz. Mater. 2003, 102, 257.

4. Seaman, J.C.; Bertsch, P.M.; Schwallie, L. Environ. Sci. Technol. 1999, 33, 938.

5. Zhou, X.; Korenaga, T.; Takahashi, T.; Moriwake, T.; Shinoda, S. Water Res. 1993, 27, 1049.

6. Kozlowski, C.A.; Walkowiak, W. Water Res. 2002, 36, 4870.

7. Chakravarti, K.A.; Chowdhury, S.B.; Chakrabarty, S.; Chakrabarty, T.; Mukherjee, D.C.A. Physicochem. Eng. Aspects 1995, 103, 59.

8. Dahbi, S.; Azzi, M.; Guardia, M. Fresenius J. Anal. Chem. 1999, 363, 404.

9. Kongsricharoern, N.; Polprasert, C. Water Sci. Technol. 1996, 34, 109.

10. Pagilla, K.; Canter, L.W. J. Environ. Engg. 1999, 125, 243.

11. Lin, C.F.; Rou, W.; LO, K.S. Water Sci. Technol. 1992, 26, 2301.

12. Sawada, A.; Mori, K.; Tanaka, S.; Fukushima, M.; Tatsumi, K. Waste Management 2004, 24, 483.

13. Mohan, D.; Sing, K.P.; Sing, V.K. Ind. Eng. Chem. Res. 2005, 44, 1027.

14. Lalvani, S.B.; Wiltowski, T.; Hubner, A.; Wetson, A.; Mandich, N. Carbon 1998, 36, 1219.

15. Ibanez, J.P.; Umestsu, Y. Hydrometallurgy 2004, 72, 327.

16. Chun, Li.; Hongzhang, C.; Zuohu, L. Biochem. 2004, 39, 54.

17. Selomulya, C.; Meeyoo, V.; Amal, R. J. Chem. Technol. Biotechnol. 1999, 74, 111.

18. Gupta, V.K.; Shrivastava, A.K.; Jain, N. Water Res. 2001, 35, 4079.

19. Aksu, Z.; Acikel, U.; Kabasakal, E.; Tezer, S. Water Res. 2002, 36, 3063.

20. Gupta, V.K.; Park, K.T.; Sharma, S.; Mohan, D. Environmentalist 1999, 19, 129.

21. Babel, S.; Kurniawan, T.A. Chemosphere 2004, 54, 951.

22. Giles, C.H.; Silva, A.P.D. Tram Faraday Sec. 1943, ISI 65.

23. Pollard, S.J.T.; Fowler, G.D.; Sollars, C.J.; Perry, R. Sci. Total Envirn. 1992, 16, 30.

24. Chatjigakis, A.K.; Pappas, P.; Proxenia, N.; Kalantzi, O.; Rodis, P.; Polissiou, M. Carbohydr. Polym. 1998, 37, 395.

25. McKay, G.; Blair, S.; Garden, J.R. Appl. Polym. Sci. 1982, 27, 3043.

26. Periasamy, K.; Namasivayam, C. Waste Management 1995, 15, 63.

27. Bhattacharya, A.K.; Venkobachar, C. J. Environ. Eng. Div-ASCE, 1984, 110, 110.

28. Goyal, N.; Jain, S.C.; Banerjee, V.C. Adv. Environ. Res. 2003, 7, 311.

29. Michelsan, L.D.; Gideon, P.G.; Pace, E.G.; Kutal, L.H. US Dept. Industry office of water research and technology, Bull. 1975, No. 74. 